\title{
高速铁路基础结构动态性能演变及服役安全的 基础科学问题
}

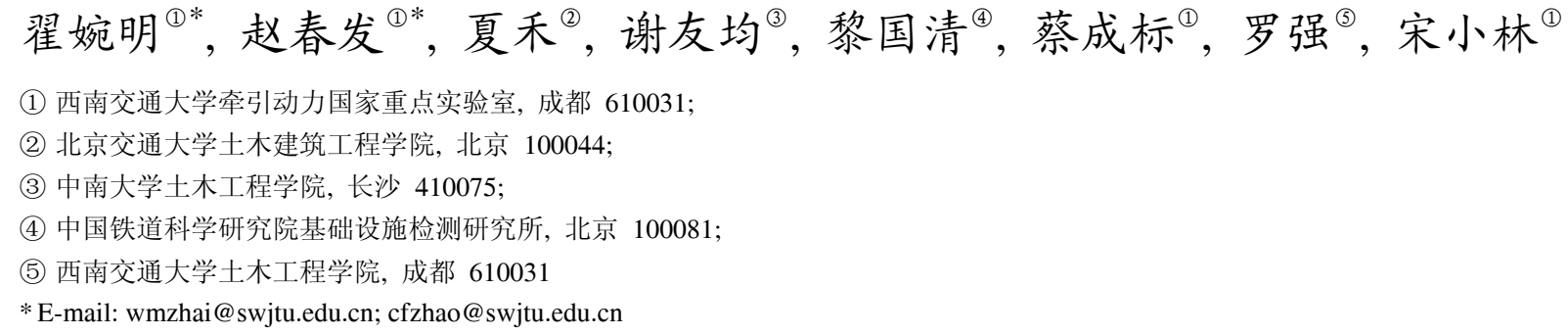

摘要中国高速铁路已经由大规模建造进入长期安全稳定运营阶段, 如何科学维护庞大规 模的高速铁路运营线路, 使高速铁路长期保持高安全、高稳定、高可靠的运营品质, 是我国现 阶段面临的重大课题. 在分析总结中国高速铁路基础结构构造特点及其复杂运营环境特点的 基础上，提出了高速铁路基础结构动态性能演变及服役安全的三个基础科学问题：环境与动 载耦合重复作用下高速铁路基础结构关键工程材料与结构动态性能演变，高速铁路基础结构 累积变形与轨面几何形态的映射关系, 基础结构劣化与高速列车-基础结构耦合系统动态性 能的相互影响及演化机制; 回顾评述了国内外在此方面的研究现状与最新进展; 指出了本领 域今后的发展趋势以及需要重点关注和加强的基础研究工作.

关键词 高速铁路 轨道结构 铁路桥梁 路基 动态性能演变 列车运行安全

\section{1 引言}

截至 2013 年底, 我国新建高速铁路营业里程已 达到 11000 余公里, 初步形成了“四纵四横”高速铁路 骨干网. 按照《中长期铁路网规划(2008 年调整)》和 《“十二五”综合交通运输体系规划》, 今后我国仍将 持续一定规模的高速铁路建设, 但中国高速铁路发 展已经从大规模建造进入长期安全稳定运营阶段, 高速铁路研究和技术创新的主题也将由设计与建造 技术逐步转向基础结构状态维护、列车运行安全管
理、骨干网运输优化以及系统灾变风险管理等安全高 效运营保障技术. “十一五”期间, 我国引进消化吸收 国外高速铁路技术，通过自主创新获得了先进、成熟 的高速铁路基础结构设计与建造技术，但在高速铁 路运营管理与维护方面, 尚缺乏系统深入的基础理 论研究. 如何科学维护庞大规模的高速铁路运营线 路? 从而使高速铁路能够长期安全稳定运营, 已成 为现阶段我国高速铁路发展面临的突出问题，而探 明高速铁路基础结构在运营过程中的动态性能演变 机制与规律，获得科学合理的基础结构服役安全评

引用格式: 翟婉明, 赵春发, 夏禾, 等. 高速铁路基础结构动态性能演变及服役安全的基础科学问题. 中国科学: 技术科学, 2014, 44: 645-660 Zhai W M, Zhao C F, Xia H, et al. Basic scientific issues on dynamic performance evolution of the high-speed railway infrastructure and its service safety (in Chinese). Sci Sin Tech, 2014, 44: 645-660, doi: 10.1360/N092014-00192 
价准则与控制方法, 是解决这一问题的关键, 是当前 迫切需要研究的重大课题.

“速度”始终是铁路发展的目标, 而“安全”是铁路 运输永恒的主题，是高速铁路设计、建造、运营与维 护的核心要求和最终落脚点. 1964 年世界上首条高速 铁路开通运营以来, 高速铁路技术已历经半个世纪 的发展，但高速铁路运营安全问题并没有得到很好 地解决, 危及高速铁路行车安全的故障和事故仍时 有发生. 究其原因, 除了对列车脱轨机理、关键材料 及结构失效机理等科学问题认识不够深刻之外, 不 了解高速铁路基础结构动态性能演变机制和规律, 不清楚高速铁路基础结构初始缺陷演化、损伤疲劳发 展规律以及特殊条件下结构状态突变对列车运行安 全的影响等, 也是其重要原因.

由钢轨、轨道板、水泥乳化沥青砂浆充填层 $(\mathrm{CA}$ 砂浆)、混凝土支承层、路基或桥梁等组成的高速铁 路基础结构, 因其组成材料的多样性、运营环境的复 杂性以及结构分布的时空效应等, 其动态性能演变 机制与规律十分复杂, 是当前高速铁路发展面临的 国际性难题. 国内外高速铁路运营实践表明, 在温 度、水等环境因素和动载荷耦合重复作用下, 服役过 程中高速铁路基础结构的构成材料的微结构会发生 变化, 关键部件可能出现损伤甚至失效, 如钢轨波 磨、扣件折断、轨道板损伤、CA 砂浆劣化等, 如图 1 所示. 而且关键材料与部件初始缺陷的动力演化, 结 构长时劣化及特殊条件下局部状态瞬时突变等, 必 然引起高速铁路基础结构服役状态与动态性能持续 改变, 逐渐导致基础结构与高速列车系统不适应、不 匹配, 并进一步恶化高速铁路线路状态与列车运行 品质, 甚至危及行车安全. 因此, 探寻高速铁路基础 结构动态性能演变机制, 揭示其性能演变对高速铁 路服役安全的影响规律, 是高速铁路技术发展的必 然趋势, 它有可能催生高速铁路基础结构运营管理 与维护技术变革, 对健全高速铁路运营安全保障体 系意义重大.

本文在分析我国高速铁路基础结构构造及其复 杂服役环境特点的基础上, 凝练出高速铁路基础结 构动态性能演变及服役安全的三个关键科学问题, 回顾评述了国内外在此方面的近期研究工作和主要 进展, 并指出该领域今后的发展趋势以及需要重点 关注和加强的研究工作, 供高速铁路技术研发人员 和运营管理部门参考应用.

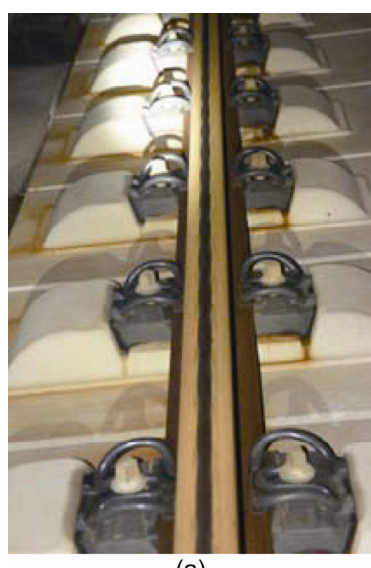

(a)

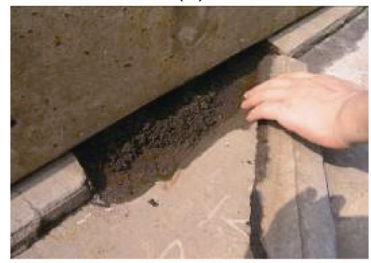

(b)

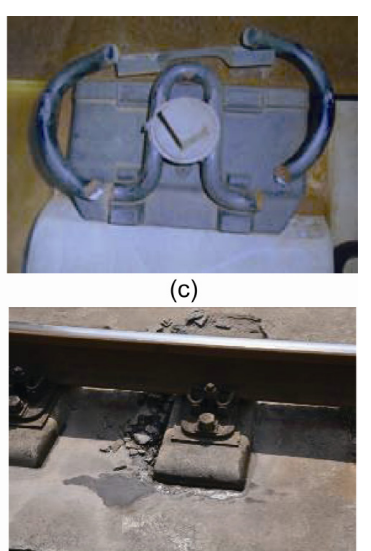

(d)

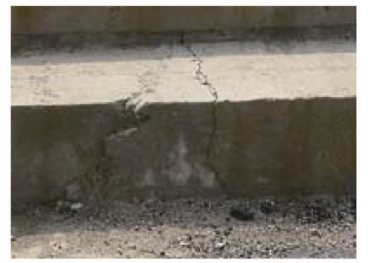

(e)
图 1 (网络版彩图)高速铁路基础结构的典型劣化现象

(a) 钢轨波浪形磨耗; (b) 沥青砂浆充填层碎裂; (c) 扣件弹条折断; (d) 道床板破损; (e) 支承层断裂

\section{2 高速铁路基础结构性能演变与服役安全 的关键科学问题}

高速移动列车系统对固定基础设施提出了近乎 苛刻的技术要求, 高平顺、高稳定、高可靠成为跨越 广衰地域空间高速铁路基础结构必须具备的终身属 性, 是高速列车长期安全、平稳、舒适运行的根本保 证. 然而, 要准确把握高速铁路基础结构在不同路 段、不同层位、不同时段的状态与性能指标，确保高 速铁路基础结构始终处于安全的服役状态, 是一个 国际性的科学技术难题.

如图 2 所示, 高速铁路基础结构是坚向多层、纵 向异性的带状系统, 它具有材料属性差别大、结构层 次多、空间跨度广、服役环境复杂等特征. 在列车动 载荷和环境载荷(水、温度等)反复作用下, 基础结构 的关键工程材料劣化、结构和部件损伤、系统状态与 性能嬗变等不可避免, 且交互影响, 本质上是一个复 杂的非线性演化过程. 这其中蕴含着尚未被充分认 识或深入研究的基础科学问题, 主要包括: 环境与动 载荷耦合重复作用下高速铁路基础结构关键工程材 料与结构动态性能的演变问题; 基础结构不同部位 


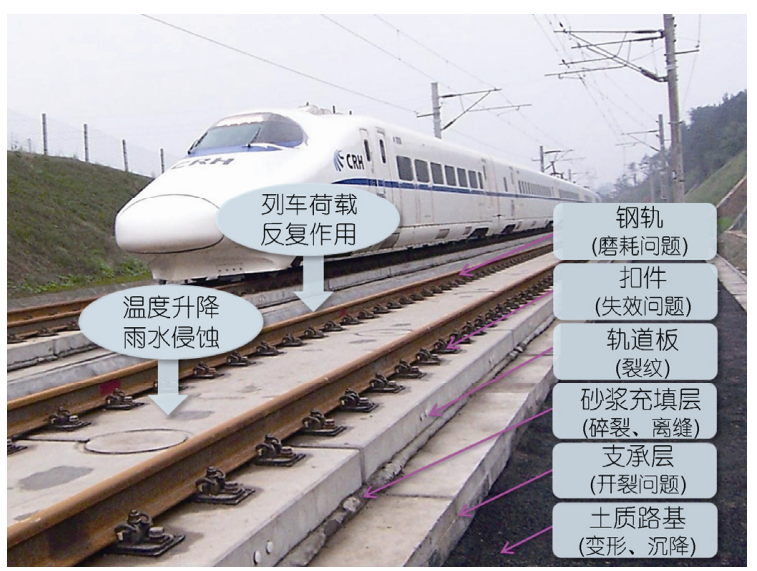

图 2 (网络版彩图)高速铁路基础结构组成及其主要 工程问题

服役状态的交互影响机制以及基础结构累积变形与 轨面几何形态的映射关系问题; 基础结构劣化与高 速列车-基础结构耦合系统动态性能的相互影响及演 化机制问题. 下面对上述三个基础科学问题展开详 细阐述.

\section{1 环境和动载荷耦合重复作用下高速铁路基础 结构关键工程材料与结构动态性能演变}

高速铁路基础结构的关键工程材料一一蒸养混 凝土、现浇混凝土和 CA 砂浆均属水泥基复合材料, 具有组成复杂、多孔性、匀质性差、极限应变小等特 点. 对水泥基复合材料进行动态力学性能试验研究, 建立其本构关系, 揭示其基本规律, 有三个尚待解决 的难题: 1) 水泥基材料动态力学性能的精确测试; 2) 动载荷(应变频率)作用下水泥基复合材料尤其是 $\mathrm{CA}$ 砂浆的动态力学性能本构关系和破坏临界值; 3) 在 温度、水和动载耦合重复作用下水泥基复合材料动态 性能的演变和劣化行为.

由于水泥基复合材料的脆性，尤其是混凝土极 限应变极小, 建立其动态应力-应变关系, 在实验技 术上需要解决应变的测试技术和实验装置. 水泥基 材料内部存在着大量不同尺寸的孔洞和裂缝, 还存 在多个界面, 它们对混凝土材料力学性能影响很大, 导致其动态力学性能的本构关系十分复杂. 再者, $\mathrm{CA}$ 砂浆含有体积分数较大的有机材料相一沥青, 沥 青凝聚相及其与水泥水化物、砂粒等物相间界面使得 其动态力学性能本构关系既不同于混凝土材料, 也 不同于沥青混合料, 迄今国内外在此方面的试验研
究极少.

高速铁路基础结构受到温度、水等环境因素和列 车动载的耦合重复作用, 这使得其关键工程材料的 动态性能演变复杂化. 首先, 在列车动载重复作用下, 水泥基复合材料内部的孔缝和界面区会发生演化, 微裂隙、微空洞等损伤的产生和演化将导致材料的软 化, 从而使得材料的动态力学性能发生劣化. 由于水 泥基材料组成的复杂性, 孔缝分布的随机性, 研究这 些微缺陷的产生和演化过程是极具挑战的科学问题; 其次, 水泥基复合材料具有较大的亲水性, 服役过程 中雨水会渗入材料内部孔缝中, 使水泥基复合材料 可能长期处于含水状态下经受着列车动载作用, 必 须考虑含水量对孔缝演化的影响, 这使得该问题更 加复杂; 再者, 孔缝中的水在低温下会结冰, CA 砂浆 中的沥青是温度敏感性材料, 在低温下将发生相转 变等, 这进一步增添了问题的难度.

组成材料的劣化必然导致相应结构及部件动态 性能的变化, 但结构宏观动态性能的演变不只是材 料微观演变的线性递进和简单叠加, 它还与结构形 式、外部载荷特性等密切相关. 因此, 为了逐步从定 性到定量地表征高速铁路基础结构的动态性能演化, 需要在结构或部件层面上研究其动态性能演化. 例 如, 无砟轨道结构服役性能的退化是列车动载荷和 温度载荷耦合作用导致的结果, 单一动载荷或温度 载荷引起的结构状态变化已经相当难解, 两者耦合 作用后的效应将更趋复杂. 我国多条高速铁路客运 专线运营实践表明, 无砟轨道己出现多种结构性损 伤与破坏, 要揭示这些现象背后的动态演化行为和 失效机理, 需要解决的科学问题有: 1) 无砟轨道结 构动载与温度力耦合作用机制; 2) 无砟轨道结构动 态性能演化路径及失效机理；3）无砟轨道结构动态 性能劣化与其上部轨面不平顺、下部桥梁或路基变形 的相互影响等.

我国新建高速铁路桥梁线路所占比重高, 在高 速度、高密度移动列车载荷和温度载荷反复作用下, 桥梁服役性能劣化问题不容忽视. 混凝土桥梁材料 及构件性能劣化、钢桥局部构件损伤和破坏、桥梁下 部基础构件失效和桥梁支座病害等, 均可能对桥面 线形产生影响, 而桥面线形又影响桥上轨道结构的 几何边界条件. 桥面大变形条件下无砟轨道板难以 正常工作, 而轨道板失稳和失效将直接影响列车运 行安全. 因此, 高速铁路桥梁材料与构件的劣化机 
理、桥上结构动力性能演变规律等是高速铁路服役安 全必需解决的科学问题. 与无砟轨道类似, 研究高速 铁路桥梁动态性能演变同样需要解决多种载荷耦合 作用机制问题和结构细观-局部-整体性能演化问题 等. 此外, 风、常遇地震、车船或漂流物撞击等均会 对桥上列车的通过安全性产生不利影响, 而上述不 利影响往往并非单独发生, 多因素共同作用下有可 能产生比单因素更加不利的列车运营条件, 因此, 综 合考虑上述不利因素对桥梁服役性能的影响, 确定 多不利因素条件下高速铁路桥梁运营安全管理措施, 也是高速铁路发展需要解决的科学技术问题.

\section{2 高速铁路基础结构累积变形与轨面几何形态 的映射关系}

高速铁路轨面以下各层结构服役状态的演变, 均会不同程度地反映为轨面几何形态的变化, 进而 影响轮轨动力作用, 并反过来影响各层结构服役状 态的演变. 因此, 掌握了轨面几何形态的变化规律, 有利于更好地预测高速铁路基础结构的某些关键服 役性能, 甚至甄别一些安全隐患; 同样, 明确了基础 结构状态与性能的演变规律, 就能合理预测轨面几 何形态变化趋势, 这对于高速铁路线路运营安全管 理从主要依赖轨面静态几何状态控制转变为静、动态 性能综合管理，具有重要的理论与现实意义.

目前，国内外采用综合检测车对高速铁路基础 设施状态进行每月数次检测, 并通过对海量检测数 据的分析为保障高速铁路运营安全、科学评估基础设 施运用状态、优化养护维修等提供了重要参考. 但是, 影响轨面形态变化的因素很多, 不仅与基础结构的 自身状态有关, 还与通过的列车载荷强度、密度及轮 轨动力特性相关, 并受到高速铁路线路地质条件、气 候环境的显著影响. 仅仅基于某条线路轨检数据获 得的经验演化模型, 并不适用于自然环境、列车运营 条件、线路结构形式等发生变化的其他高速铁路线路. 要获得稍具普遍意义的高速铁路线路几何状态形成、 发展与恶化模型, 在统计分析检测数据的基础上, 还 需要结合高速列车与基础结构耦合动力学研究成果, 研究基础结构不同部位服役状态的交互影响机制, 揭示基础结构变形与轨面几何形态的映射关系, 这 在系统研究的规模、深度与广度上较目前基本上依赖 检测数据的归纳分析有了质的飞跃.

要揭示高速铁路基础结构变形与轨面几何形态
的映射关系, 需要掌握高速铁路线路状态变化特点 与表征方法, 探明高速铁路基础结构变形的基本规 律, 并构建两者之间的映射模型, 如图 3 所示. 首先, 从海量检测数据中准确提取尽可能多的有用信息, 国内外已提出一些数据处理与分析方法, 但是, 由于 对轮轨高频动力作用、线下结构状态变化对轨面微、 宏观几何形态的长期影响机制的认识尚不充分, 检 测数据的分析处理仍面临着轨道几何状态敏感要素、 特征长度等难以合理确定的困境. 再者, 基础结构累 积变形受路基工后沉降、路基与桥涵等结构过渡区域 差异沉降、无砟轨道及桥梁等工程结构变形等多个因 素的影响, 其累积变形成因及发展规律相当复杂. 例 如, 由自然水、温环境交替变化和列车动载荷重复作 用引起的路基累积塑性变形问题极为复杂, 从理论 上揭示其变形机制十分困难; 而且, 由于高速铁路路 基变形的微量性, 以及现有本构模型的不完善和计 算参数的变异性, 路基结构长期累积塑性变形的有 效控制和可靠预测, 还面临极大的科学挑战.

目前, 研究高速铁路基础结构变形与轨面几何 形态之间映射关系所面临的主要难题有：1) 列车动 载荷和环境载荷耦合反复作用下，层间结构几何形 位的相互影响与协调机制；2）反映各层结构状态长 时演化、协调变形以及变形传递机制的映射模型. 服 役过程中, 各层结构几何形位与动态性能发生变化, 层间界面状态也随之发生变化, 界面之间力和位移 的传递机制相当复杂. 例如, 要了解砂浆材料劣化、 充填层剥离或破碎对轨道板受力与变形的影响, 无 论是现场测试还是理论分析都面临挑战. 又如, 基础 结构累积变形与轨面几何形态之间存在着动态的映 射关系, 复杂的车轨动力耦合、环境与列车载荷耦

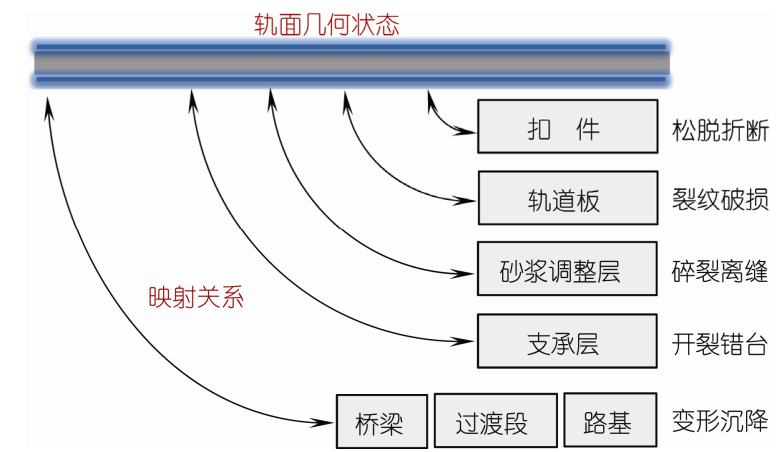

图 3 (网络版彩图)高速铁路基础结构变形与轨面几何形态 的映射 
合、结构层间动态耦合等决定了这一映射的节点规模 大、路径多、非线性强等特点. 因此, 如何定量化描 述关键参数如结构不连续、刚度不均匀、动力性能不 匹配等引起的轨面几何形态变化趋势, 如何确定不 同波长范围轨道几何形状的主要映射路径等, 在研 究方法和手段上都面临极大困难.

\section{3 基础结构劣化与高速列车-基础结构耦合系统 动态性能的相互影响及演化机制}

高速铁路长期运营过程中, 高速列车-基础结构 耦合动力响应既是车辆、轨道及桥梁(或路基)服役性 能的综合表现, 也是基础结构服役性能进一步演变 的催化剂, 两者之间互为因果、相互影响. 由于基础 结构的组成材料属性不同、结构部件多、结构动力性 能差别大等特点, 高速车辆-基础结构耦合动力学系 统规模大、自由度高且非线性强, 其耦合作用机制颇 为复杂. 而且, 服役过程中关键工程材料劣化、部件 损伤以及基础结构不均匀变形等持续变化, 使得耦 合系统动力响应复杂多变. 随着结构和部件损伤程 度不断加深, 可能改变车辆-基础结构耦合作用关系, 促使关键材料及结构部件的动力性能进一步恶化甚 至失效, 还会加剧耦合系统主要激扰源一一轨道不平 顺的恶化, 从而激发出更大的系统响应, 加速材料、 部件的劣化进程以及累积变形的增长. 如图 4 所示, 这种恶性循环的累积, 势必给高速铁路运营带来安 全隐患, 并影响高速列车运行平稳性.

要揭示基础结构服役性能和高速列车-基础结构

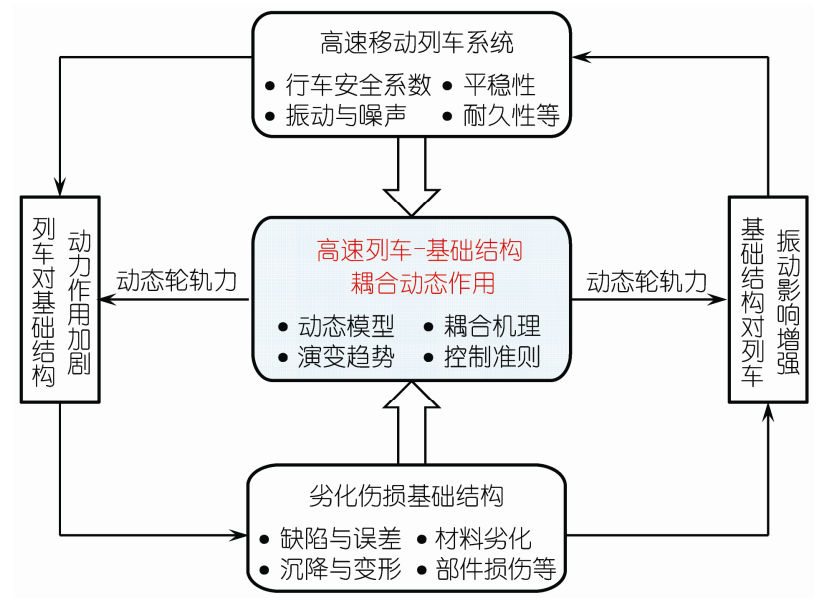

图 4 (网络版彩图)高速车辆-基础结构动态相互作用演化 机制
动态耦合作用的相互影响机制, 主要面临的难题是: 在关键工程材料性能劣化、结构部件损伤、基础累积 沉降与不均匀变形等持续变化情况下, 车辆与基础 结构耦合作用机制及系统动力性能的演变问题. 然 而, 在目前的高速铁路车辆-基础结构耦合动力学研 究中, 尚未充分考虑材料劣化、部件损伤、结构失效、 基础不均匀变形等对车辆-基础结构耦合作用方式及 其动力性能的影响.

值得注意的是, 材料劣化、部件损伤还会持续改 变轨道支承性能, 恶化轨道动力不平顺; 而路基沉降 与不均匀变形的发展也会引起轨面几何状态不断变 化, 恶化线路几何偏差. 此外, 基础结构服役性能劣 化还将影响其层间耦合作用机制及动力响应传递与 衰减规律等. 因此, 研究基础结构服役状态与高速车 辆-基础结构耦合动态性能的相互影响机制, 还需要 考虑轨面几何状态的恶化与结构层间耦合作用方式 的演变, 但是, 目前建立考虑这些因素的理论模型还 十分困难.

因此, 在高速车辆-基础结构耦合动力系统中, 通过引入关键工程材料与结构部件的劣化失效模型, 研究基础结构动态性能演变对高速列车运行安全性 与平稳性的影响, 并提出相应的安全控制准则, 实现 基于基础结构性能演变的高速列车服役状态安全评 估, 面临着艰难的科学挑战.

\section{3 高速铁路基础结构动态性能演变与服役 安全的研究现状及主要进展}

\section{1 基础结构关键材料动态性能劣化研究}

1) 混凝土材料动态性能演变与劣化

混凝土材料动态特性研究最早可上溯至 1917 年

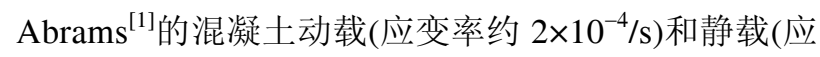
变率约 $8 \times 10^{-6} / \mathrm{s}$ ) 压缩试验, 发现了混凝土抗压强度 存在应变速率敏感性. 但是, 直到 20 世纪 60 年代以 后, 混凝土动态特性才受到更多学者的重视, 促进了 其试验技术与分析方法的进步 ${ }^{[2,3]}$. Bischoff 和 Perry ${ }^{[4]}$ 总结了加载速率对混凝土抗压强度影响的研究成果, 分析了加载速率对强度、弹性模量、临界应变、泊松 比、吸能能力的影响. Malvar 与 Ross ${ }^{[5]}$ 对 20 世纪有关 载荷速率对混凝土单轴动态抗拉强度影响的研究工 作进行了回顾与评述. 他们的研究表明, 国内外在混 
凝土单轴应力状态下的动态拉、压性能方面已取得许 多共识. 例如, 动态加载中测得的混凝土强度比静态 抗压强度可能高 25\% 30\%, 且应变速率越大, 强度 增加幅度越大; 弹性模量随着加载速率增加而增加, 但没有抗压强度那么明显; 混凝土强度等级越高, 其 强度对应变频率敏感性越小, 刚性骨料使混凝土强 度的应变速率敏感性减弱; 混凝土含水率越大, 其强 度对应变速率敏感性增强.

混凝土动力试验技术发展是推进混凝土动态性 能研究的决定性因素之一. 按照试验设备动力源特 点及所适用应变速率范围, 主要有液压试验系统、落 锤试验系统、压杆试验系统和射弹试验系统等. 由于 混凝土材料的脆性, 其动态性能的实验技术难度很 大, Georgin 和 Reynouard ${ }^{[6]}$ 提出应变直接测量技术, 并设计了损伤 “冻结”实验, 测得了混凝土的动态应 力-应变曲线和损伤演化规律.

混凝土材料动态性能研究中有两方面还少见报 道, 其一是蒸养混凝土材料, 已有研究主要针对常温 或标准条件下的养护混凝土 ${ }^{[7 ~ 10]}$, 而在 $50 \sim 60^{\circ} \mathrm{C}$ 水蒸 汽环境下养护的混凝土动态性能则鲜见报道. 其二 是缺乏混凝土承受高速列车载荷作用频率的试验研 究, 现有研究大多是混凝土大坝和军事设备承受地 震和爆炸产生的高频率冲击载荷时的动态性能研究. 对受到温度、水和高速列车动载耦合反复作用下，混 凝土材料内部损伤和缺陷的演变及其导致的动态性 能劣化行为的研究几乎还是空白.

2) 水泥乳化沥青砂浆动态性能演变与劣化

水泥乳化沥青砂浆是由水泥、乳化沥青、细砂和 其他添加剂组成的有机-无机复合砂浆, 用于高速铁 路无砟轨道的砂浆充填层. 国外高速铁路用水泥乳 化沥青砂浆的研究主要集中在日本和德国, 分别研 发了 CA 砂浆和 BZ 砂浆, 两者主要组分基本相同, 但配比有所差异, 因而其力学性能不同.

2002 年, 我国在进口日本 CA 砂浆的基础上, 研 制了新型 $\mathrm{CA}$ 砂浆, 先后在秦沈客运专线、遂渝线等 进行了各种形式轨道板 CA 砂浆应用试验, 从试验段 应用情况来看, CA 砂浆出现了严重的劣化现象. 2007 年京津城际高速铁路引进了德国 BZ 砂浆技术, 但其 长期应用效果依然不很理想. 2006 年底我国设立“无 砟轨道技术再创新”科研攻关项目, 由中国铁道科学 研究院、中南大学等单位承担了其中的 CA 砂浆技术 攻关. 在参考和借鉴日本与德国技术的基础上，两个
单位分别自主研发了多种型号的 CA 砂浆, 并在京 广、京沪、广深港、哈大、杭长等高速铁路和客运专 线上应用双线总里程超过 $5000 \mathrm{~km}$.

无论是 CA 砂浆还是 BZ 砂浆, 目前公开发表的 相关报道中, 列入砂浆技术标准的力学性能指标主 要是静态力学性能(强度和弹模); 在砂浆耐久性方面, 也只有抗冻性、耐候性和抗疲劳性能指标; 国外尚未 见有关 $\mathrm{CA}$ 砂浆和 $\mathrm{BZ}$ 砂浆动态性能演变及其劣化行 为的研究报道. 近年来, 我国进行了 $\mathrm{CA}$ 砂浆耐久 性、劣化机理和流变性与施工质量等方面的研究，揭 示了砂浆充填层劣化机理的“冲击-动水压理论”; 提 出了抗水性和低温抗裂性的耐久性评价指标以及屈服 应力与塑性黏度的流变性指标等 ${ }^{[11]}$. 周锡玲等人 ${ }^{[12]}$ 开展了湿含量对 CA 砂浆热变形的影响研究. 田冬梅 等人 ${ }^{[13,14]}$ 分析了水、温度对 $\mathrm{CA}$ 砂浆动态力学性能、 热变形与层间界面黏接性能的影响, 得到了如图 5 所 示的不同沥灰比 $\mathrm{CA}$ 砂浆动弹性模量和损耗角随温度 的变化规律, 为无砟轨道砂浆填充层性能演变与伤
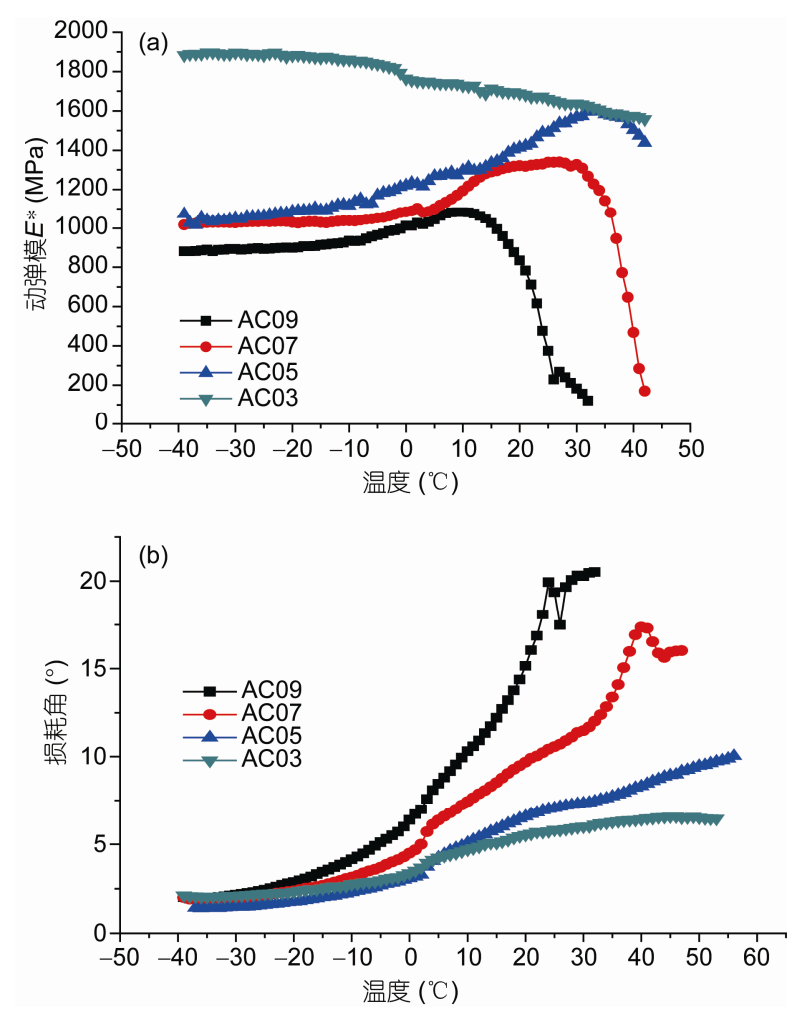

图 5 (网络版彩图)不同水泥乳化沥青净浆体试件动态性能 随温度的变化

(a) 动弹性模量; (b) 损耗角 
损失效研究提供了基础. 但是, 总体上国内外对 CA 砂浆动态性能及其劣化行为还知之甚少.

\section{2 无砟轨道动态性能演变与失效机理研究}

无砟轨道在我国高速铁路中已得到广泛应用, 主要包括板式、双块式无砟轨道及道岔区长枕埋入式 无砟轨道. 调查结果表明, 我国高速铁路运营线上无 砟轨道己出现诸多结构性损伤与破坏, 主要有轨道 板、底座或支承层裂纹, 砂浆充填层碎裂, 道床板与 支承层、轨道板与砂浆充填层之间黏结失效破坏, 预 制轨枕与现浇道床板之间界面裂缝, 扣件弹条断裂 等. 这些现象大体可归纳为层间联结失效、结构部件 损伤开裂两大类问题.

\section{1) 无砟轨道层间联结失效}

无砟轨道结构层与层之间的可靠联结对其服役 性能有重要影响, 层间破坏也是无砟轨道结构性能 劣化的典型现象, 但国内外对此研究很少. 近年来, 内聚力模型被广泛应用于黏结界面开裂过程分析, 国内外学者提出了多个界面力-界面相对位移模型, 使用界面强度来预测开裂损伤的产生 ${ }^{[15 \sim 18]}$. 内聚力 模型基于损伤力学来描述裂纹尖端的损伤, 采用断 裂力学中的断裂能来控制裂纹的扩展, 它将界面裂 纹的产生和扩展过程都放在了同一模型中描述, 比 较容易在有限元程序中实现. Zhu 和 $\mathrm{Cai}^{\left[{ }^{[19]}\right.}$ 采用内聚 力模型模拟了温度和列车动载荷作用下 CRTS II 型 无砟轨道的轨道板与 $\mathrm{CA}$ 砂浆界面剥离和破碎行为, 获得了温度与列车动载荷作用下 $\mathrm{CA}$ 砂浆界面应力与 损伤变化规律(图 6), 初步展示了无砟轨道界面损伤 的发生机理与发展过程. 邵丕彦等人 ${ }^{[20]}$ 在哈大高速 铁路施工现场, 对尚未铺轨的 CRTS I 型轨道板高程 及与 $\mathrm{CA}$ 砂浆垫层间离缝进行全天跟踪测试, 研究了 温度变化对轨道板温度尧曲变形及与砂浆垫层间离 缝的影响. Muramoto 等人 ${ }^{[21]}$ 对饱和黏土路基上的无 砟轨道展开了实尺模型试验, 解释了无砟轨道与黏 土路基界面的破坏机理, 并通过试验提出了有效的 预防措施. Colla 等人 ${ }^{[22]}$ 综合应用高频雷达、冲击回波 和超声回波等无损检测方法现场检测了无砟轨道轨 枕与轨道之间的松动与失效问题.

无砟轨道界面间的动水压力也是加速其层间失 效的一个重要影响因素, 动水压力下无砟轨道结构 层间的失效破坏与水在其中的流动有密切关系, 开 裂过程往往伴随着与裂隙水流的相互耦合作用. 徐

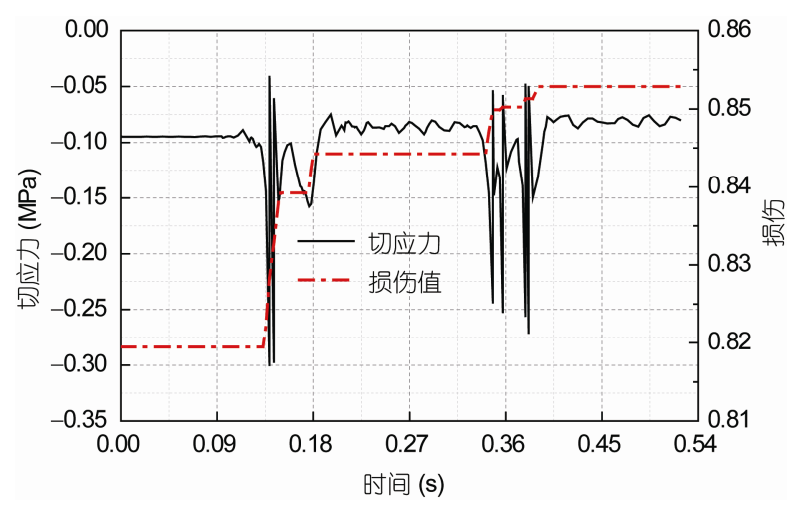

图 6 (网络版彩图)温度与列车动载荷作用下轨道板与 $\mathrm{CA}$ 砂浆界面应力与损伤变化

桂弘 ${ }^{[23]}$ 建立无砟轨道裂纹内水压力计算模型, 开展 循环荷载作用下裂纹水压力模型试验, 初步研究了 动水压力的作用特性及裂纹扩展特性. 国内外对重 力坝高压水䢃裂问题进行了较多的试验与数值模拟 分析 ${ }^{[2426]}$, 其研究理论与方法对考虑动水压作用的 无砟轨道损伤破坏研究具有参考价值.

\section{2) 无砟轨道结构部件损伤}

$\mathrm{CA}$ 砂浆层、底座和支承层等部件的损伤是无砟 轨道另一主要破坏类型. Takahashi 和 Sekine ${ }^{[27]}$ 通过 现场调研和轨道板材料试验, 分析了日本寒冷地区 无砟轨道轨道板劣化的影响因素, 发现轨道板日照 时间更长的南侧更易发生冻融损伤, 材料的碱硅酸 反应会引起轨道板的劣化. 朱胜阳和蔡成标 ${ }^{[28-30]}$ 建 立 CA 砂浆材料的统计损伤本构模型, 开发相应的三 维有限元本构子程序, 研究了列车动载荷作用下 $\mathrm{CA}$ 砂浆层的损伤发展规律及其动态行为的演变; 还采 用混凝土损伤塑性模型来描述双块式无砟轨道道床 板的力学行为, 分析了变温和列车动载荷作用下道 床板损伤演变规律; 建立含道床裂纹的车辆-双块式 无砟轨道垂向耦合动力学模型, 探讨了裂纹对道床 振动特性的影响. 赵坪锐和刘学毅 ${ }^{[11]}$ 考虑双块式无 砟轨道支承层开裂情况, 研究了裂缝间距、支承层厚 度和弹性模量对结合式双层结构抗弯刚度的影响. 任娟娟等 ${ }^{[32}$ 基于钢筋混凝土黏结-滑移理论, 分析了 配筋率、钢筋直径和混凝土强度对道床板裂纹宽度、 间距及钢筋应力的影响. 林红松 ${ }^{[33]}$ 使用轮轨系统动 力学和有限单元法, 对含裂纹的无砟轨道静、动力特 性开展了初步研究.

此外, 国内外还对无砟轨道结构疲劳损伤破坏 
问题展开了初步研究. Poveda 等人 ${ }^{[34]}$, Konings ${ }^{[35]}$,

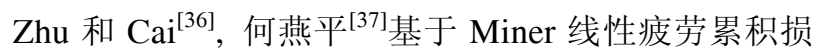
伤模型和钢筋混凝土 S-N 曲线, 初步分析了服役期间 复杂载荷下无砟轨道结构的疲劳寿命. 毛锦达 ${ }^{[38]}$ 模 拟板式无砟轨道 CA 砂浆荷载-高频振动-高低温环境, 分析了 CRTS I 型和 CRTS II 型 CA 砂浆的抗疲劳性 能. 朱胜阳和蔡成标 ${ }^{[39]}$ 基于连续损伤力学理论和边 界面概念, 建立了无砟轨道结构在循环载荷作用下 的疲劳损伤模型，该模型不仅能够反映结构部件的 疲劳损伤非线性演变规律, 还可以展现其疲劳损伤 分布形态的全过程. 蔡成标和朱胜阳 ${ }^{[40]}$ 运用列车-线 路耦合动力学理论及仿真软件, 通过系统分析高速 铁路无砟轨道不平顺谱对轮轨力大小及统计特性的 影响规律, 指出高速铁路无砟轨道结构的疲劳检算 载荷取为静轮重的 1.5 倍是合理的.

高速铁路无砟轨道在我国的应用时间还很短, 国内对无砟轨道长期运营过程中出现的损伤、破坏、 失效与服役环境的相互关系研究才刚刚起步, 特别 是在无砟轨道结构疲劳载荷表征方法、结构失效机理 及运用安全性评定等方面的研究还非常贯乏, 亟需 开展系统深入的研究.

\section{3 高速铁路桥梁动力性能演变及服役安全研究}

在桥梁材料性能改变对桥梁车振性能影响研究 方面, 目前的研究主要集中于考虑大跨度铁路斜拉 桥索结构几何非线性和物理非线性时的车桥动力相

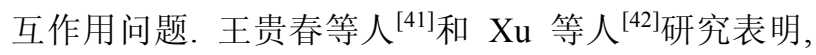
考虑材料非线性因素时斜拉桥车激响应与材料线性 假定下的计算结果显著不同. 王凡和郭向荣 ${ }^{[43]}$ 分析 了考虑徐(温)变的连续梁拱桥车桥耦合振动, 指出混 凝土徐变效应引起的桥面变形会引起附加轨道不平 顺, 有必要在高速铁路桥梁动力分析中加以考虑. $\mathrm{CaO}$ 等人 ${ }^{[44]}$ 分析了在高速铁路桥墩附近进行基础施 工对于桥上列车运行性能的影响. Hou 等人 ${ }^{[45]}$ 开展了 钢混结合梁桥剪力键损伤识别的数值分析. Law 和 $\mathrm{Zhu}^{[46]}$ 研究指出结构损伤将大幅增加桥梁在车辆动 载荷作用下的变形, 并有可能致使桥梁破坏, 因此在 桥梁模型中应准确反映结构的损伤程度和损伤模式.

高速铁路桥梁动力性能演变及服役安全研究对 列车系统、轨道系统和桥梁系统模型的完备性提出了 新的要求. 近年来, 国内学者系统建立了考虑三维轮 轨接触关系和桥轨耦合关系的高速车辆-轨道-桥梁动
力相互作用模型及其分析方法, 为准确评估桥梁动力 性能和桥上运行列车的走行性提供了技术手段 ${ }^{[47 \sim 52]}$. 在铁路桥梁车激振动研究中, 除考虑车辆动载荷之 外，一些学者还考虑风、地震、温度变化、撞击等诸 多因素, 并针对各因素对桥上车辆通行安全性的影 响进行了研究 ${ }^{[53 \sim 59]}$. 在桥梁服役过程中上述多个因 素有可能共同发生作用，一般而言这样的耦合作用 较单一因素更加不利, 但多因素耦合作用对高速列 车桥上行车安全的影响研究, 目前鲜见报道.

现代桥梁工程对致命性灾害(如高烈度地震)引 起的桥梁结构损伤、破坏及其危害性评估有较多研究, 但对常遇中小灾变引起的桥梁结构局部损伤有可能 影响桥梁服役性能的研究不多. 其中, 在地震及洪水 冲刷对桥梁结构损伤及刚度削弱方面, 已有研究多 基于桥梁的静态损伤及静态剩余健康度评估. 在地 震对混凝土桥梁的损伤研究中, 主要关注地震导致 的材料性能劣化及其非线性破坏模式 ${ }^{[60]}$; 在钢桥方面 主要关注钢构件在地震载荷下的失效及屈曲失稳 ${ }^{[61]}$; 洪水冲刷对桥梁的损伤则主要以灾后桥梁基础剩余 刚度来表达 ${ }^{[62]}$. 目前尚未有研究涉及灾后桥梁服役 性能评估与行车安全性之间的关系问题.

\section{4 高速铁路路基结构长期累积变形研究}

国内外广泛开展了列车载荷重复作用和自然水 温环境交替变化情况下路基土工材料累积塑性变形 的研究, 研究的重点包括以下三个方面. 其一是应力 水平、密实度、含水量等因素对循环载荷作用下路基 累积塑性变形的影响. Morgan ${ }^{[63]}$ 开展的三轴试验结 果表明, 轴向累计塑性应变直接与偏差应力有关. Thom 和 Brown ${ }^{[64]}$ 对白云岩碎石材料的试验表明，应 力水平、密实度、含水量对累计塑性变形有显著影响. 陈云敏等人 ${ }^{[65]}$ 采用原状与重塑软黏土进行循环三轴 试验, 得出了应力水平对结构性软土静力与动力变 形特性的影响. 付兵先等人 ${ }^{[66]}$ 通过模拟路基冻融循 环过程, 研究在冻融条件下延迟时间对水泥改良低 液限粉土的动强度、动弹性模量、动变形以及超孔隙 水压力的影响. 其二, 是累积塑性变形的计算模型研 究. 基于动三轴试验结果, 以应力水平和循环载荷作 用次数为变量, 国内外提出了多种经验计算模型, 如 指数模型、对数模型、幂函数模型等, 这些模型形式 简单，应用方便. 但正如 Pérez 等人 ${ }^{[67]}$ 所指出的, 不 同应力水平下累计塑性变形的变化规律存在较大差 
异. 也有学者基于弹塑性理论建立本构模型来研究 路基累积塑性变形的发展趋势 ${ }^{[68,69]}$. 其三, 是关于循 环载荷作用下累计塑性变形呈现出不同特征状态的 探讨. Werkmeister ${ }^{[70]}$ 认为不同应力水平下累计塑性 应变呈现塑性安定、塑性蠕变和增量破坏三种不同响 应. Minassian ${ }^{[71]}$ 以体积塑性应变为判别依据, 同样将 循环载荷作用下的累计塑性应变划分为三个状态. 刘刚 ${ }^{[72]}$ 以累积塑性变形演化呈现出收敛与否、收敛发 散快慢的现象为特征, 提出循环载荷作用下土工填 料累积塑性变形的演化呈现快速稳定、长期稳定、长 期破坏和快速破坏的四个状态类别(图 7), 并建立基 于累积塑性变形速率发展趋势的数学判别准则.

在高速铁路过渡段路基沉降方面, 已有工作多 集中在过渡段施工与沉降控制技术研究, 以及过渡 段动力学特性分析. 罗强 ${ }^{[73]}$ 开展了高速铁路路桥过 渡段动力特性分析, 并在秦沈客运专线进行了路桥 过渡段动力性能及沉降试验研究. 孟凡会等人 ${ }^{[74]}$ 根 据秦沈客运专线路桥过渡段的路基面纵、横向动应力 测试结果, 模拟分析了动载作用下过渡段的沉降变 形沿纵向、横向及路基深度方向的变化规律. 铁道科 学研究院在京津城际高速铁路武清段设置了沉降观 测段, K83+007 K86+800 段观测结果表明: 2011 年 9 月至 2013 年 3 月, 武清站站台区间发生了 19.6 27.5 $\mathrm{mm}$ 均匀沉降量, 绝对沉降量最大达 $206.5 \mathrm{~mm} ; 2013$ 年 1 月至 2013 年 3 月, 武清段轨道控制网沉降量在 0 8.1 mm, K86+166 K86+443 段沉降趋势明显, 沉降 量在 4.0 8.1 mm. 图 8 给出了该区段沉降曲线图, 可 以发现沉降量较大的区段出现在翠亨路中桥和其两 端路桥过渡段附近.
可见, 通过大量理论与试验研究, 国内外对高速 铁路路基长期累积变形发展规律有一定认识, 也建 立一些经验与理论预测模型, 但尚未达成一致性结 论, 为准确预测与合理评估高速铁路路基累积沉降, 仍有待开展系统性的深入研究.

\section{5 高速铁路线路几何状态及其演变规律研究}

国内外对铁路线路几何状态 (主要指轨道累积沉 降和轨道不平顺)及其演变规律的研究主要针对有砟 轨道. 近年来, 我国在多条高速铁路运营线上开展了 线路沉降观测与轨道不平顺实测分析. 但是, 在高速 铁路基础变形与轨面几何形状之间的映射方面, 国 内外研究极少.

1) 高速铁路轨道几何不平顺特征及功率谱

影响轨道几何不平顺发展的影响因素众多, 世 界各国普遍采用轨检车检测轨道几何形位, 经统计

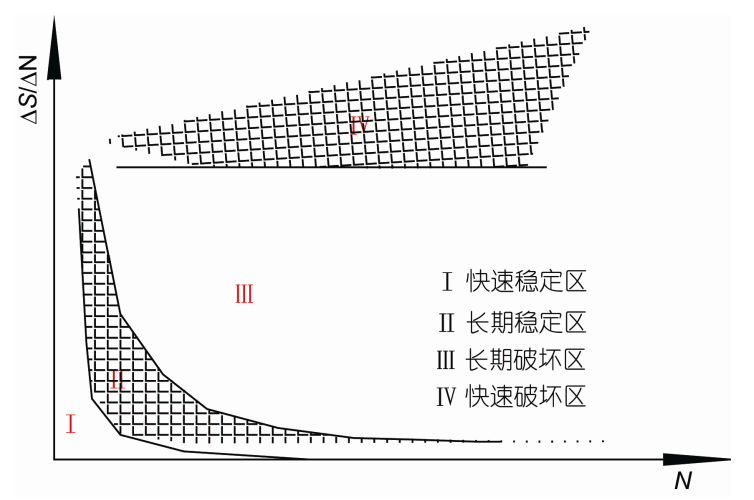

图 7 (网络版彩图)基于累积变形速率表达的路基变形状态 划分

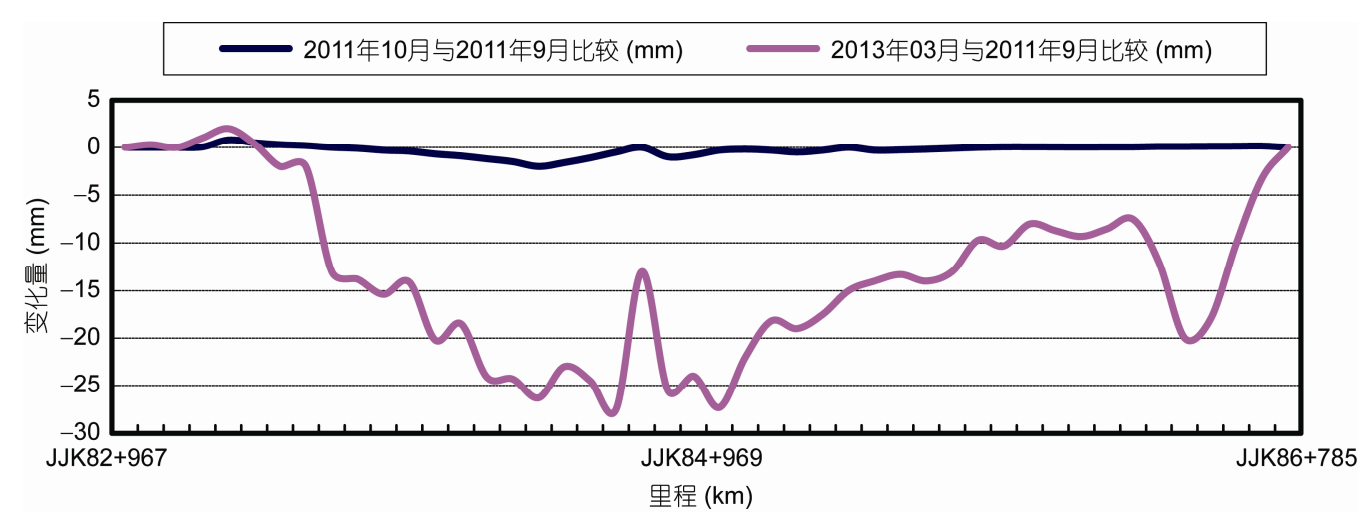

图 8 (网络版彩图)京津城际高速铁路武清段轨道控制网沉降对比曲线 
分析不平顺幅值与波长特征, 提出适合各国铁路实 际情况的轨道不平顺谱及其分级评定方法.

英国、法国、德国、日本、美国等早已发布了通 过测量分析得出的轨道不平顺谱. 我国轨道不平顺 谱研究起步较早, 20 世纪 90 年代, 铁道科学研究院 在分析京广、京哈、京沪等多条提速干线轨道不平顺 特征的基础上, 提出中国提速干线通用轨道不平顺 谱及其分级评定方法, 建议将我国干线铁路轨道谱 划分为时速 200 和 $160 \mathrm{~km}$ 等级提速线路、时速 120 $\mathrm{km}$ 普通线路共 3 个等级, 将提速干线铁路谱图划分 为 6 个区域, 分别评定为优秀、良好、较好、一般、 较差和极差 ${ }^{[75 ~ 77]}$. 随着京津城际高速、沪宁高速铁路 等开通运营, 我国利用多条高速铁路实测轨道不平 顺数据开展了高速轨道谱研究 ${ }^{[78 ~ 80] . ~}$. 对于高速铁路 无砟轨道波长范围为 2 200 $\mathrm{m}$ 的轨道不平顺, 我国已 提出相应的轨道不平顺谱拟合公式 ${ }^{[81]}$

$$
S(f)=\frac{A}{f^{k}},
$$

式中, $f$ 是轨道不平顺空间频率, $A$ 和 $k$ 是拟合系数.

根据高速铁路无砟轨道结构类型和线桥设备台 账, 分析轨道不平顺谱特征发现: 在连续等跨简支梁 上的高低不平顺存在波长为简支梁跨度的周期性不 平顺; CRTS II 型板式无砟轨道高低不平顺存在波长 等于轨道板长的周期性不平顺; CRTS I 型板式无砟 轨道高低不平顺存在波长为底座板长的周期性不平 顺; 轨距和轨向不平顺存在波长等于钢轨定尺长度 的周期性不平顺; 轨道周期性不平顺在轨道不平顺 谱上存在相应倍频谱峰.

周期性轨道不平顺不宜用谱密度表征, 研究发 现, 采用倍频能量表示周期不平顺比较合理. 在我国 高速铁路中, 连续等跨 $32 \mathrm{~m}$ 简支梁和 CRTS II 型板 式无砟轨道轨道板变形引起的周期性高低不平顺谱 峰较大, 相应的谱峰倍频能量参见表 1 和 2 .

我国高速铁路无砟轨道谱研究还有待于积累实 测样本, 不断完善; 对于高速铁路有砟轨道谱, 还需 要持续研究, 尽快提出相应的轨道谱拟合公式, 并且 还需要在长波和短波不平顺检测、数据处理方法及其 不平顺特征分析上进行系统研究.

2) 基础结构变形与轨道几何状态的映射关系

我国高速铁路轨道不平顺实测结果表明, 无砟 轨道及桥梁结构单元长度在实测谱中有清晰表现, 这意味基础结构变形与轨道几何不平顺有较为明确

\section{表 $132 \mathrm{~m}$ 简支梁引起的高低不平顺倍频能量}

\begin{tabular}{ccccc}
\hline 倍频数 & 1 & 2 & 3 & 4 \\
\hline 频率 $(1 / \mathrm{m})$ & 0.0306 & 0.0615 & 0.0918 & 0.1221 \\
能量 $\left(\mathrm{mm}^{2}\right)$ & $8.3812 \times 10^{-2}$ & $8.1582 \times 10^{-3}$ & $2.9141 \times 10^{-3}$ & $2.1222 \times 10^{-3}$ \\
\hline
\end{tabular}

表 2 CRTS II 轨道板引起的高低不平顺倍频能量

\begin{tabular}{ccc}
\hline 倍频数 & 1 & 2 \\
\hline 频率 $(1 / \mathrm{m})$ & 0.1543 & 0.3086 \\
能量 $\left(\mathrm{mm}^{2}\right)$ & $1.9501 \times 10^{-2}$ & $4.2867 \times 10^{-4}$ \\
\hline
\end{tabular}

的映射关系, 但目前国内外在此方面的研究极少. 陈 兆玮等人 ${ }^{[82,83]}$ 推导了桥上铺设单元板式无砟轨道、纵 连板式轨道条件下桥墩沉降和钢轨变形映射关系的 解析表达式, 其研究结果表明: 理论解析值与有限元 计算结果能很好吻合; 钢轨随桥墩沉降发生的变形 与沉降量成正比, 并与扣件间距、钢轨弹性模量和截 面惯量等参数有关; 常用跨度高速铁路桥梁的桥墩 沉降会对高速行驶的列车产生低频激励, 该激振频 率与车体的垂向自振频率相近, 将对车体振动产生 较大影响.

在有砟轨道累积沉降与轨道几何状态发展之间 的关系方面, 早期美国运输中心、北美铁道协会、英 国、日本等均开展了轨道下沉与高低不平顺标准差关 系的试验分析, 但各国试验结果差异较大, 多年来此 方面的国内外研究进展不大 ${ }^{[84]}$. 广井生马的研究表 明轨道不平顺进展速率标准差是轨道下沉标准差的 1.22 倍; 杉山德平在此基础上, 结合轨检车实测数据, 分析得出了轨道下沉与高低不平顺的关系模型 ${ }^{[85]}$. 高建敏 ${ }^{[86]}$ 和翟婉明 ${ }^{[87,88]}$ 利用既有线轨检车检测数据, 结合车辆-轨道耦合动力学数值分析, 对轨道累积下 沉和高低不平顺发展之间的关系进行了研究. 总之, 国内外对基础结构变形与轨道几何不平顺发展之间 的对应关系有一些定性认识, 但由于这种关系具有 随机性和复杂性, 其定量化研究还十分困难.

\section{6 基础结构动态性能演变对高速列车运行安全 性与平稳性的影响及其控制}

1) 轨道不平顺对列车运行性能的影响

轨道不平顺对轮轨动力作用、基础结构性能演变 和列车运行安全平稳性能均有重要影响, 国内外对 此开展了大量的理论与试验研究. 
Takai ${ }^{[89]}$ 研究了新干线上长波、中波和短波不平 顺对列车乘座舒适性、运行安全性和轮轨噪声的影响, 通过谱分析提出采用 $40 \mathrm{~m}$ 弦检测不平顺以保证日本 高速列车运行安全与平稳性. Esveld ${ }^{[00]}$ 实测分析轨道 不平顺和车辆响应之间的关系, 得到了不平顺激励对 轨道力、车体振动加速度的传递函数. 罗林等人 ${ }^{[91]}$ 、 张格明 ${ }^{[92]}$ 通过车辆动力学分析, 研究了轨道高低、轨 向和水平不平顺对准高速列车运行性能的影响, 提出 了轨道不平顺控制准则与方法. 翟婉明 ${ }^{[93]}$ 创建了车 辆-轨道耦合动力学理论, 分析了各种轨道不平顺激 扰下轮轨动力响应的基本特征及其对行车安全平稳 性的影响; 蔡成标等人 ${ }^{[94,95]}$ 在此基础上研究了不同 类型轨道不平顺对货车动力性能的影响, 提出了轨 道几何不平顺安全限值. 陈果等人 ${ }^{[96]}$ 开展车辆-轨道 耦合系统随机振动研究, 提出了时速 $250 \mathrm{~km}$ 高速铁 路轨道不平顺的安全管理建议. 练松良和黄俊飞 ${ }^{[97]}$ 对轨道随机不平顺与不同类型车辆车体加速度之间 的关系进行了相干分析, 得出引起客车和货车较大 动力响应的轨道不平顺不利波长. 杨飞等人 ${ }^{[98]}$ 分析 了轨道不平顺对 $\mathrm{CRH} 2$ 车辆动力学性能的影响, 给出 时速 300 350 km 高速铁路轨道不平顺管理建议波长. 翟婉明和王开云研究了钢轨表面剥离、波浪形磨耗、 焊接不平顺和桥墩沉降等对高速列车与基础结构动 力作用的影响, 给出了车速 $300 \mathrm{~km} / \mathrm{h}$ 时各类不平顺 波长和波幅对高速列车运行性能指标的影响规律, 如图 9 和 10 所示.

当前, 我国需要更全面地开展高速铁路轨道不 平顺及其演化发展对列车运行安全性和舒适性的影

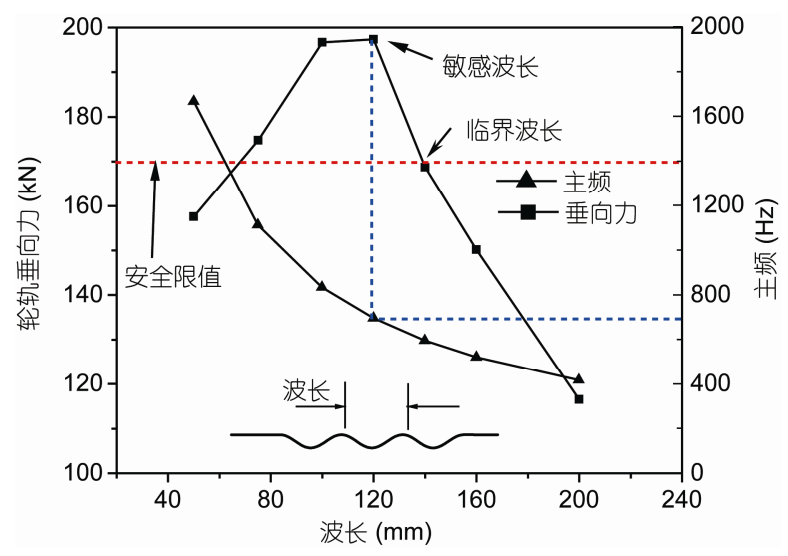

图 9 (网络版彩图)高速铁路波磨不平顺波长对轮轨力的 影响

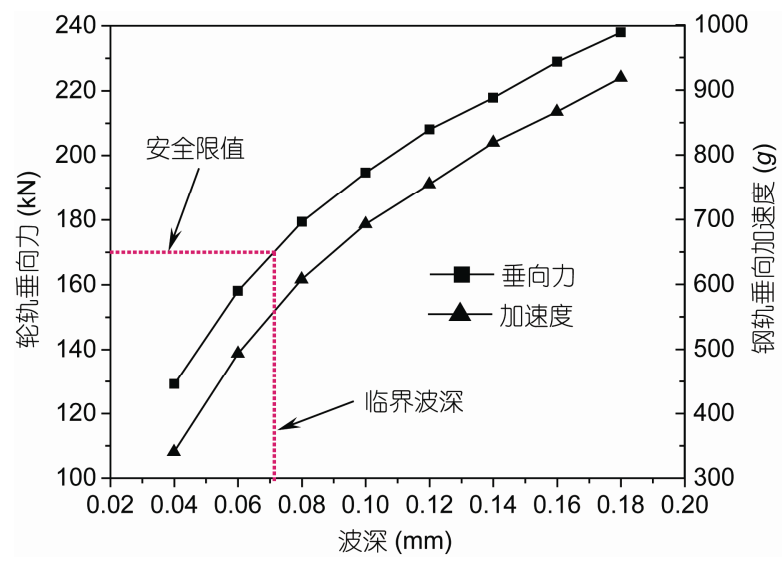

图 10 (网络版彩图)高速铁路波磨不平顺波深对轮轨力的 影响

响研究, 特别需要加强轨道不平顺对高速铁路无砟 轨道、桥梁、路基等动态性能演变及其服役性能的影 响研究.

2) 基础结构性能演变对列车运行性能的影响

我国车辆-轨道耦合动力学、列车-轨道-桥梁动力 相互作用理论与方法已日㮹成熟, 但以往的研究多 集中在特定工况下列车与线路系统的瞬时动力学行 为分析, 目前需要逐步扩展到考虑线路状况长期演 变的高速铁路大系统动力学研究.

为了考虑基础结构参数变化对车辆-轨道系统动 力学行为的影响, 一些学者提出采用概率极限状态 法与可靠度分析法研究不确定参数条件下列车的行 车性能. Mohammadzadeh 等人 ${ }^{[99]}$ 采用响应曲面法, 基于车辆动力学仿真获得了列车脱轨的极限状态函 数, 并使用 3 级可靠度方法评估列车脱轨概率, 指出 轨道随机不平顺的发展与钢轨及其他工程材料性质、 养护维修情况和运量等因素有关. Cho 等人 ${ }^{[100]}$ 建立 高速列车-轨道-桥梁三维有限元模型, 选取既能反映 系统动力性能恶化也能反映主要结构载荷时变特性 的关键输入参数, 运用改进的响应曲面法分析动力 系统的可靠性, 从而实现对不确定性系统的定量化 分析, 以保证高速铁路的安全服役. 响应曲线法与车 轨耦合动力学分析的紧密结合已成为高速铁路基础 结构参数优化设计的热点. 但是, 概率极限状态法与 可靠度分析法还只是笼统地考虑了结构参数的时变 性与随机性, 它还不能反映基础结构服役过程中性 能演变的时序性和规律性.

在德国、日本和中国高速铁路先后出现事故之后, 
一项清醒的认识是对车辆、轨道和基础结构关键部件 必须进行长期监控, 国内外也投入大量人力物力建 立高速铁路实时监控系统, 相关学者还开展了车辆 或轨道状态识别与评估方法研究 ${ }^{[101 ~ 103]}$. 但是, 不论 是高速铁路实时监测还是极限状态法等，均难以揭 示基础结构性能长时演变与车辆-轨道耦合动力作用 的相互影响, 不能对长期服役过程中高速列车运行 状态与基础结构性能演变给予合理准确的预测. 为 了获得基础结构性能演变规律及其服役安全的控制 方法, 还需要在推进高速铁路关键材料劣化、主要结 构与部件损伤、系统失效机理与规律研究的基础上, 系统开展高速铁路基础结构性能演变与列车运行安 全性与舒适性的综合研究.

\section{4 发展趋势及今后的研究方向}

根据高速铁路基础结构动态性能演变与服役安 全的研究现状与最新进展, 展望本领域发展趋势, 今 后我国应重点关注并加强以下几方面研究工作.

1) 在高速铁路基础结构关键材料动态性能劣化 研究方面, 需要开展关键工程材料动态特性试验与 表征方法研究, 材料动态性能的微结构参数相关性 研究, 以及材料动态性能的水、温度、动载等多因素 依赖性研究. 其中, 重点需要在多因素耦合重复作用 下 CA 砂浆劣化行为和破坏机理研究方面取得突破, 并逐步建立高速铁路基础结构关键材料动态性能评 价技术体系.

2) 在无砟轨道动态性能演变与失效机理研究方 面, 需要针对性地开展我国无砟轨道结构动载荷与 温度力耦合作用机制研究, 并在此基础上重点开展 无砟轨道结构累积损伤演变过程及其破坏形态的理 论与试验研究, 最终建立高速铁路无砟轨道结构损 伤评价方法及技术指标体系, 确定层间失效、结构损 伤开裂、疲劳裂纹扩展等结构安全服役限值, 用于指 导无砟轨道结构养护维修.

3) 在高速铁路桥梁动力性能演变及服役安全研
究方面, 需要加强关键材料劣化、结构部件损伤对桥 梁动力性能的影响研究, 开展多种不利因素共同作 用下桥梁服役性能劣化行为与规律研究, 要建立材 料变异、结构损伤、环境及灾害等耦合作用下高速铁 路桥梁服役性能演变和状态控制的关键技术指标体 系，确立基于车桥响应预测和长期监测数据的桥梁 结构损伤评估与预警方法.

4）在高速铁路路基累积变形及服役性能演变研 究方面, 需要加强高速铁路路基土工材料在动、静载 荷及复杂环境条件下的累积变形规律研究，探索基 于变形时效性的路基土工结构状态分析理论与评估 方法，推动高速铁路路基由“变形定值驱动的结构分 析”向“变形状态驱动的结构分析”发展, 在此基础上 还需要逐渐细化路基面与地基两类差异沉降的控制 限值，完善高速铁路路基沉降控制指标体系.

5) 在高速铁路线路几何状态演变及轨道不平顺 研究方面, 今后要充分利用运营线上高速铁路线路 几何状态检测数据, 开展中国高速铁路线路几何状 态演变规律研究. 需要将高速列车-基础结构耦合动 力学分析与实测轨道不平顺分析相结合, 开展基础 结构累积变形与轨面几何形态的映射关系研究, 揭 示动载荷反复作用下基础结构不同部位服役状态的 交互影响机制，建立高速铁路线路几何状态发展预 测模型，提出不同运营速度等级的轨道几何不平顺 控制限值.

6) 在基础结构性能演变对高速行车安全平稳性 的影响及其控制研究方面, 需要利用高速铁路轨道、 桥梁、路基等结构动态性能演变的研究成果, 开展高 速列车与不同服役状态基础结构的动态相互作用研 究, 从铁路大系统动力学角度, 研究线路几何状态演 化、轨道支承状态劣化、桥梁结构变形、基础不均匀 沉降等对高速行车安全性与舒适性的影响规律, 探 寻确保高速铁路基础结构安全服役的状态控制方 法，从而细化不同运行速度等级下基础结构服役状 态的安全限值, 完善高速铁路基础结构安全维护标 准体系.

\section{参考文献}

1 Abrams D A. Effect of rate of application of load on the compressive strength of concrete. P ASTM, 1917, 17: 364-374

2 胡时胜. 研究混凝土材料动态力学性能的实验技术. 中国科学技术大学学报, 2007, 37: 1312-1319

3 间东明，林臬．影响混凝土动态性能的因素分析．世界地震工程, 2010, 26: 30-26 
4 Bischoff P H, Perry S H. Compressive behaviour of concrete at high strain rates. Mater Struct, 1991, 24: 425-450

5 Malvar L J, Ross C A. Review of strain rate effects for concrete in tension. ACI Mater J, 1998, 95: 435-439

6 Georgin J F, Reynouard J M. Modeling of structures subjected to impact: Concrete behavior under high strain rate. Cement Concrete Comp, 2003, 25: 131-143

7 Ragueneau F, Gatuingt F. Inelastic behavior modelling of concrete in low and high strain rate dynamics. Comput Struct, 2003, 81: $1287-1299$

8 Erzar B, Forquin P. An experimental method to determine the tensile strength of concrete at high rates of strain. Exp Mech, 2010, 50: 941-955

9 Kulik V M, Semenov B N, Boiko A V, et al. Measurement of dynamic properties of viscoelastic materials. Exp Mech, 2009, 49: 417-425

10 Zhang X X, Yu R C, Ruiz G, et al. Effect of loading rate on crack velocities in HSC. Int J Impact Eng, 2010, 37: 359-370

11 中南大学水泥乳化沥青砂浆课题组. 板式无砟轨道水泥乳化沥青砂浆研发研究报告. 长沙: 中南大学, 2010

12 周锡玲, 郑克仁, 谢友均, 等. 湿含量对水泥乳化沥青砂浆热变形的影响. 建筑材料学报, 2013, 16: 814-82

13 田冬梅, 邓德华, 田青, 等. 水对水泥乳化沥青砂浆动态力学性能的影响. 硅酸盐学报, 2013, 41: 49-55

14 田冬梅, 邓德华, 彭建伟, 等. 温度对水泥乳化沥青砂浆层与混凝土层间界面黏结的影响. 铁道学报, 2013, 35: 1-8

15 Tvergaard V, Hutchinson J W. The relation between crack growth resistance and fracture process parameters in elastic-plastic solids. J Mech Phy Solids, 1992, 40: 1377-1397

16 Xu X P, Needleman A. Numerical simulation of fast crack growth in brittle solids. J Mech Phy Solids, 1994, 42: 1397-1434

17 De Moura M F S F, Goncalves J P M, Marques A T, et al. Modeling compression failure after low velocity impact on laminated composites using interface elements. J Compos Mater, 1997, 31: 1462-1479

18 Alfano G, Crisÿeld M A. Finite element interface models for the delamination analysis of laminated composites: mechanical and computational issues. Int J Numer Meth Eng, 2001, 50: 1701-1736

19 Zhu S Y, Cai C B. Interface damage and its effect on vibrations of slab track under temperature and vehicle dynamic loads. Int J Non-lin Mech, 2014, 58: 222-232

20 郡丕彦, 李海燕, 吴韶亮, 等. CRTSI 型轨道板温度变形及与砂浆垫层间离缝的测试研究. 中国铁道科学, 2013, 34: 18-22

21 Muramoto K, Sekine E, Nakamura T. Roadbed degradation mechanism under ballastless track and its countermeasures. Q Rep RTRI, 2006, 47: 222-227

22 Colla C, Krause M, Maierhofer C, et al. Combination of NDT techniques for site investigation of non-ballasted railway tracks. NDT E Int, 2002, 35: 95-105

23 徐桂弘. 列车动荷载下无砟轨道含水裂纹受力特性及影响研究. 博士学位论文. 成都: 西南交通大学, 2013

24 贾金生, 李新宇, 郑璀莹. 特高重力坝考虑高压水擘裂影响的初步研究. 水利学报, 2006, 37: 1509-1515

25 Alfano G, Marfla S, Sacco E. A cohesive damage-friction interface model accounting for water pressure on crack propagation. Comput Method Appl M, 2006, 196: 192-209

26 Mitchell S L, Kuske R, Peirce A P. An asymptotic framework for the analysis of hydraulic fractures: The impermeable case. J Appl Mech, 2007, 74: 365-372

27 Takahashi T, Sekine E. Evaluation of factors contribution to deterioration of track-slab in cold areas. Q Rep RTRI, 2011, 52: 149-155

28 Zhu S Y, Cai C B. Damage evolution and dynamic response of cement asphalt mortar layer of slab track under vehicle dynamic load. Sci China Technol Sci, 2014, 57: in press

29 朱胜阳, 蔡成标. 温度和列车动载荷作用下双块式无砟轨道道床板损伤特性研究. 中国铁道科学, 2012, 33: 6-12

30 朱胜阳, 蔡成标. 含裂纹的双块式无砟轨道道床垂向振动特性分析. 铁道学报, 2012, 34: 82-86

31 赵坪锐, 刘学毅. 双块式无碴轨道开裂支承层的折减弹性模量. 西南交通大学学报, 2008, 43: 459-464

32 任娟娟, 刘学毅, 赵坪锐. 连续道床板裂纹计算方法及影响因素. 西南交通大学学报, 2010, 45: 34-38

33 林红松. 基于断裂和损伤力学的无砟轨道静动力特性研究. 博士学位论文. 成都: 西南交通大学, 2009

34 Poveda E, Yu R C, Lancha J C, et al. Finite element analysis on the fatigue damage under compression of a concrete slab track. In: The 8th International Conference on Fracture Mechanics of Concrete and Concrete Structure. Barcelona, Spain: International Center for Numerical Methods in Engineering, Gran Capita, 2013. 850-861

35 Konings P. A study on the lifetime aspects of the Rheda 2000 track system. Dissertaion for the Doctoral Degree. Delft: Delft University of Technology, 2005

36 Zhu S Y, Cai C B. Fatigue life prediction of CRTS I ballastless slab track. In: Proceedings of the 3rd International Conference on Transportation Engineering. ASCE, 2011. 1714-1719

37 何燕平. CRTS III 型板式无砟轨道疲劳特性研究. 硕士学位论文. 成都: 西南交通大学, 2011 
38 毛锦达. 板式无砟轨道 CA 砂浆抗冻与抗疲劳性能研究. 硕士学位论文. 杭州: 浙江工业大学, 2012

39 朱胜阳，蔡成标.一种高速铁路无砟轨道混凝土结构疲劳损伤模型. 中国科学：技术科学, 2014, 44: 714-721

40 蔡成标, 朱胜阳, 刘秀波, 等. 高速铁路无砟轨道疲劳检算轮载的动力学分析. 中国科学: 技术科学, 2014, 44: 707-713

41 王贵春, 潘家英, 张欣. 大跨度铁路斜拉桥车桥塊合振动非线性分析. 应用力学学报, 2008, 25: 524-528

42 Xu Y L, Zhang N, Xia H. Vibration of coupled train and cable-stayed bridge systems in cross winds. Eng Struct, 2004, 26: 1389-1406

43 王凡，郭向荣. 考虑徐(温)变的连续梁拱桥车桥耦合振动分析. 重庆交通大学学报(自然科学版), 2009, 28: 986-990

44 Cao Y M, Xia H, Lu W L, et al. A numerical method to predict riding comfort induced by foundation construction close to high-speed railway bridge. J Rail Rapid Transit, 2014, doi: 10.1177/0954409713519087

45 Hou Z M, Xia H, Zhang Y L. Dynamic analysis and shear connector damage identification of steel-concrete composite beams. Steel Compos Struct, 2012, 13: 327-341

46 Law S S, Zhu X Q. Dynamic behavior of damaged concrete bridge structures under moving vehicular loads. Eng Struct, 2004, 26: 1279-1293

47 翟婉明, 夏禾. 列车-轨道-桥梁动力相互作用理论与工程应用. 北京: 科学出版社, 2011

48 蔡成标. 高速铁路列车-线路-桥梁耦合振动理论及应用研究. 博士学位论文. 成都: 西南交通大学, 2004

49 Zhai W, Xia H, Cai C, et al. High-speed train-track-bridge dynamic interactions part I: Theoretical model and numerical simulation. Int J Rail Transport, 2013, 1: 3-24

50 Zhai W, Wang S, Zhang N, et al. High-speed train-track-bridge dynamic interactions part II: Experimental validation and engineering application. Int J Rail Transport, 2013, 1: 25-41

51 Guo W W, Xia H, De Roeck G, et al. Integral model for train-track-bridge interaction on the Sesia viaduct: Dynamic simulation and critical assessment. Comput Struct, 2012, 112-113: 205-216

52 Zhang N, Xia H. Dynamic analysis of coupled vehicle-bridge system based on inter-system iteration method. Comput Struct, 2013, 114-115: 25-34

53 Guo W W, Xia H, Zhang N. Dynamic responses of Tsing Ma Bridge and running safety of trains subjected to Typhoon York. Int J Rail Transport. 2013, 1: 181-192

54 张敏, 张楠, 夏禾. 大跨度铁路悬索桥风-车-桥耦合动力分析. 中国铁道科学, 2013, 34: 34-39

55 Zhang T, Xia H, Guo W W. Analysis on running safety of train on bridge with wind barriers subjected to crosswind. Wind Struct, 2013, 17: 203-225

56 Zhang Z C, Zhang Y H, Lin J H, et al. Random vibration of a train traversing a bridge subjected to traveling seismic waves. Eng Struct, 2011, 33: 3546-3558

57 Xia C Y, Lei J Q, Zhang N, et al. Dynamic analysis of a coupled high-speed train and bridge system subjected to collision load. J Sound Vib, 2012, 331: 2334-2347

58 Xia C Y, Xia H, Zhang N, et al. Effect of truck collision on the dynamic response of train-bridge systems and running safety of high-speed trains. Int J Struct Stab Dy, 2012, 13: 1-18

59 王少林, 翟婉明. 地震作用下高速列车-线路-桥梁系统动力响应. 西南交通大学学报, 2011, 46: 56-62

60 Bassam A, Iranmanesh A, Ansari F. A simple quantitative approach for post earthquake damage assessment of flexure dominant reinforced concrete bridges. Eng Struct, 2011, 33: 3218-3225

61 Caglayan O, Ozakgul K, Tezer O, et al. Evaluation of a steel railway bridge for the dynamic and seismic loads. J Constr Steel Res, 2011, 67: $1198-1211$

62 Lin C, Bennett C, Han J, et al. Integrated analysis of the performance of pile-supported bridges under scoured conditions. Eng Struct, 2012 , 36: $27-38$

63 Morgan J R. The response of granular materials to repeated loading. In: Proceedings of the 3rd Australian Road Research Board Conference. Sydney: Australian Road Research Board, 1966. 1178-1192

64 Thom N H, Brown S F. Effect of moisture on the structural performance of a crushed-Limestone road base. Transport Res Rec: J Transport Res Board, 1987, 1121: 50-56

65 陈云敏, 陈颖平, 黄博. 应力水平对结构性软黏土静力和动力变形特性影响的试验研究. 岩石力学与工程学报, 2006, 25: 937-945

66 付兵先, 张千里, 史存林, 等. 冻融循环条件下延迟时间对水泥改良低液限粉土动力特性影响试验研究. 中国铁道科学, 2010, 31: 9-15

67 Pérez I, Medina L, Romana M G. Permanent deformation models for a granular materials used in road pavements. Constr Build Mater, 2006, 20: 790-800

68 Chazallon C, Hornych P, Mouhoubi S. Elastoplastic model for the long-term behavior modeling of unbound granular materials in flexible pavements. Int J Geomechan, 2006, 6: 279-289

69 Wichtmann T, Rondón H A, Niemunis A, et al. Prediction of permanent deformations in pavements using a high-cycle accumulation model. 
J Geotech Geoenviron, 2010, 136: 728-740

70 Werkmeister S. Permanent deformation behavior of unbound granular materials in pavement constructions. Dissertaion for the Doctoral Degree. Dresden: TU Dresden, 2003

71 Minassian G H. Behavior of granular materials under cyclic and repeated loading. Dissertaion for the Doctoral Degree. Fairbanks: University of Alaska, 2003

72 刘钢. 基于长期累积变形演化状态控制的高速铁路基床结构设计方法研究. 博士学位论文. 成都: 西南交通大学, 2013

73 罗强. 高速铁路路桥过渡段动力学特性分析及工程试验研究. 博士学位论文. 成都: 西南交通大学, 2003

74 孟凡会, 侯永峰, 吴涛. 路桥过渡段的三维数值模拟分析. 岩土力学, 2007, 28: 849-854

75 铁道部科学研究院铁道建筑研究所. 我国干线轨道不平顺功率谱的研究. 北京: 铁道部科学研究院, 1999

76 陈宪麦, 王澜, 陶夏新, 等. 我国干线铁路通用轨道谱的研究. 中国铁道科学, 2008, 29: 73-77

77 陈宪麦, 王澜, 陶夏新 等. 我国干线铁路轨道平顺性评判方法的研究. 中国铁道科学, 2008, 29: 21-27

78 Liu XB, Tao K, Tian XY, et al. Characteristic analysis of PSD of track irregularities of ballastless tracks on high-speed railway. The 2nd International Conference on the Railway Engineering, Beijing, July 20-21, 2012. 228-232

79 陈秀方, 金守华, 曾华亮. 运专线轨道不平顺功率谱分析. 中国工程科学, 2008, 10: 56-59

80 李再帏, 练松良. 武广高速铁路轨道不平顺谱特征分析. 郑州大学学报, 2013, 34: 52-55

81 康熊, 刘秀波, 李红艳, 等. 高速铁路无砟轨道不平顺谱. 中国科学：技术科学, 2014, 44: 687-696

82 陈兆玮, 孙宇, 翟婉明. 高速铁路桥墩沉降与钢轨变形的映射关系( I ): 单元板式无砟轨道系统. 中国科学: 技术科学, 2014, 44: $770-777$

83 陈兆玮, 孙宇, 翟婉明. 高速铁路桥墩沉降与钢轨变形的映射关系( II): 纵连板式无砟轨道系统. 中国科学: 技术科学, 2014 , 44: 778-785

84 高建敏, 翟婉明. 铁路有砟轨道下沉破坏研究进展. 铁道学报, 2008, 20: 97-104

85 佐藤吉彦. 新轨道力学. 北京: 中国铁道出版社, 2001

86 高建敏. 铁路有砟轨道下沉及高低不平顺发展预测研究. 博士学位论文. 成都: 西南交通大学, 2008

87 高建敏, 翟婉明. 车辆一轨道耦合动力学在轨道下沉研究中的应用. 西南交通大学学报, 2007, 42: 431-435

88 高建敏, 翟婉明, 徐涌. 有碴轨道下沉变形参数影响分析. 交通运输工程学报, 2007, 7: 15-20

89 Takai H. Maintenance of track with long-wave track irregularity on Shinkansen. Q Rep RTRI, 1990, 31: 128-131

90 Esveld C. Modern Railway Track. 2nd ed. Zaltbommel: MRT-Productions, 2001

91 罗林, 张格明, 吴旺青, 等. 轮轨系统轨道不平顺状态的控制. 北京: 中国铁道出版社, 2006

92 张格明. 线路轨道不平顺管理标准的研究. 中国铁道科学, 1995, 16: 31-40

93 翟婉明. 车辆-轨道耦合动力学. 第 3 版. 北京: 科学出版社, 2007

94 蔡成标, 王其昌. 轨道扭曲不平顺安全限值的研究. 西南交通大学学报, 1994, 29: 229-334

95 蔡成标, 翟婉明, 王其昌. 轨道几何不平顺安全限值的研究. 铁道学报, 1995, 17: 82-87

96 陈果, 翟婉明, 左洪福. $250 \mathrm{~km} / \mathrm{h}$ 高速铁路轨道不平顺的安全管理. 西南交通大学学报, 2001, 36: 495-499

97 练松良, 黄俊飞. 客货共运线路轨道不平顺不利波长的分析研究. 铁道学报, 2004, 26: 111-115

98 杨飞, 黎国清, 刘金朝. 时速 300 350 km 高速铁路轨道不平顺管理波长研究. 铁道建筑, 2013, 1: 86-90

99 Mohammadzadeh S, Sangtarashha M, Molatefi H. A novel method to estimate derailment probability due to track geometric irregularities using reliability techniques and advanced simulation methods. Arch Appl Mech, 2011, 81: 1621-1637

100 Cho T, Song M K, Lee D H. Reliability analysis for the uncertainties in vehicle and high-speed railway bridge system based on an improved response surface method for nonlinear limit states. Nonlinear Dynam, 2010, 59: 1-17

101 Feldmann U, Kreuzer E, Pinto F. Dynamic diagnosis of railway tracks by means of the Karhunen-Loève transformation. Nonlinear Dynam, 2000, 22: 193-203

102 Grond F. Safety certificate: An audification performance of high-speed trains. AI \& Society, 2012, 27: 293-295

103 Kim S S, Park C, Kim Y G. Parameter characteristics of rail inspection measurement system of HSR-350x. J Mech Sci Technol, 2009, 23: 1019-1022 


\title{
Basic scientific issues on dynamic performance evolution of the high-speed railway infrastructure and its service safety
}

\author{
ZHAI WanMing ${ }^{1}, \mathrm{ZHAO} \mathrm{ChunFa}^{1}, \mathrm{XIA} \mathrm{He}^{2}, \mathrm{XIE}$ YouJun $^{3}$, LI GuoQing $^{4}, \mathrm{CAI}$ ChengBiao ${ }^{1}$, \\ LUO Qiang $^{5} \&$ SONG XiaoLin ${ }^{1}$
}

${ }^{1}$ State Key Laboratory of Traction Power, Southwest Jiaotong University, Chengdu 610031, China;

${ }^{2}$ School of Civil Engineering, Beijing Jiaotong University, Beijing 100044, China;

${ }^{3}$ School of Civil Engineering, Central South University, Changsha 410075, China;

${ }^{4}$ Infrastructure Inspection Research Institute, China Academy of Railway Sciences, Beijing 100081, China;

${ }^{5}$ School of Civil Engineering, Southwest Jiaotong University, Chengdu 610031, China

The development of Chinese high-speed railway has entered the new stage of long-term safe and stable operations from the stage of large-scale constructions. How to scientifically maintain the large-scale operating lines, with the aim of holding a high operation quality of the high-speed railway characterized with a high safety, a high stability, and a high reliability during its long-term operation, is a key research task currently faced by China. Based on the summary and analysis of construction characteristics and operation environments of Chinese high-speed railway infrastructures, this paper proposes three key scientific issues on dynamic performance evolution of the high-speed railway infrastructure and its service safety. They include dynamic performance evolution of the critical materials and structures of the high-speed railway infrastructures subjected to repeated train and environment loads, the mapping relationship between the cumulative deformation of the high-speed railway infrastructures and the rail surface geometry, and the interaction and evolution mechanism between the infrastructure deteriorations and dynamic performances of the coupled high-speed train-infrastructure system. Then this paper reviews the current research status and the latest progress on the above three scientific issues, and points out the developing trends and the fundamental research works that need to be focused on and strengthened in the future.

high-speed railway, track structure, railway bridge, subgrade, dynamic performance evolution, train running safety doi: 10.1360/N092014-00192 